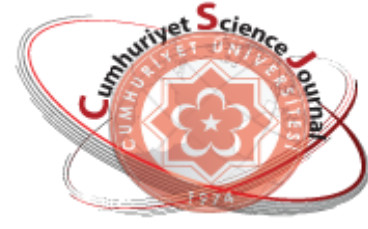

e-ISSN: $2587-246 X$

ISSN: 2587-2680

\section{Cumanoriyot Science Journal}

est

Cumhuriyet Sci. J., Vol.40-1(2019) 141-149

\title{
Flip Bifurcation and Stability in a Discrete-Time Prey-Predator Model with Allee Effect
}

Figen KANGALGIL

Sivas Cumhuriyet University, Faculty of Science, Department of Mathematics, Sivas, TURKEY

Received: 08.01.2019; Accepted: 19.02.2019

http://dx.doi.org/10.17776/csj.509898

\begin{abstract}
In this paper, a discrete-time prey-predator model with Allee effect is considered. The dynamical behavior of the model is investigated. The existence and stability conditions of the coexistence fixed point of the model are analyzed. By using bifurcation theory, it is shown that the model undergoes flip bifurcation. Also, numerical simulations are presented to support the obtained theoretical results.
\end{abstract}

39A33, 37G35, 39A30.

Keywords: Flip Bifurcation; Stability, Discrete-Time Prey-Predator Model, Allee effect, Population Model.

\section{Kesik Zamanlı Allee Etkili bir Av-Avcı Modelinin Kararlıı̆̆ı ve Flip Çatallanması}

Özet. Bu makalede, Allee etkili kesik zamanlı bir av-avcı modeli ele alındı. Modelin dinamik davranışları incelendi. Modelin her iki türün bir arada olduğu denge noktasının varlığı ve kararlılık şartları elde edildi. Çatallanma teorisi kullanılarak, modelin flip çatallanmaya gittiği gösterildi. Elde edilen teorik sonuçların doğruluğunu göstermek için nümerik gösterimlere yer verildi.

39A33, 37G35, 39A30.

Anahtar Kelimeler: Flip Çatallanma, Kararlılık, Kesik Zamanlı Av-Avcı Modeli, Allee etkisi, Popülasyon Modeli.

\section{INTRODUCTION}

The dynamics of prey-predator interaction is an important subject in bio-mathematical literature. So, many researchers studied the dynamical behavior of the prey-predator system and contributed a lot to the improvement of these models [1-21]. In literature, many species have no overlap between generations, and their population evolves in discrete-time steps. These population models are expressed by difference equations. Moreover, discrete-time models have richer dynamics than continuous models. Therefore, the researchers' interest has recently increased to discrete- time systems [1-16,25].

In [21], the author has considered the following continuous-time model with Allee effect on prey population:

$$
\begin{aligned}
& \left.\frac{d x}{d t}=\mathrm{x}\left(\mathrm{b}_{1}-a_{11} \mathrm{x}\right) \frac{x}{\beta+x}+a_{12} \mathrm{x} y\right) \\
& \frac{d y}{d t}=\mathrm{y}\left(\mathrm{b}_{2}-a_{22} y\right)
\end{aligned}
$$


where $x(\mathrm{t})$ and $\mathrm{y}(\mathrm{t})$ represent population densities of prey and predator at time $t$, respectively. $b_{i}, i=1,2$ are the intrinsic growth rate of the prey $x$ and predator $y, \frac{b_{i}}{a_{i i}}, i=1,2$ is the carrying capacity of prey and predator, respectively. $a_{12}$ reflects the efficiency of every single population $y$ that can contribute to population $x$. The term $\frac{x}{\beta+x}$ is Allee effect. The author investigated the local and global property of the fixed point of the system (1) with Allee effect on prey population [21].

We consider discrete- time version of the system (1) with Allee effect on predator species by applying the forward Euler scheme as follows:

$$
\begin{aligned}
& x_{t+1}=x_{t}+\delta\left(\mathrm{x}_{t}\left(\mathrm{~b}_{1}-a_{11} \mathrm{x}_{t}\right)+a_{12} \mathrm{x}_{t} y_{t}\right) \\
& y_{t+1}=y_{t}+\delta\left(\mathrm{y}_{t} \mathrm{~b}_{2} \frac{y_{t}}{m+y_{t}}-a_{22} y_{t}\right)
\end{aligned}
$$

where $\delta>0$ is the step size, $x(\mathrm{t})$ and $\mathrm{y}(\mathrm{t})$ represent population densities of prey and predator at time $t$, respectively. All parameters are positive constants. The term $f(\mathrm{y})=\frac{y}{m+y}$ is called Allee effect where $m$ is Allee constant [17-20]. The Allee effect is a crucial phenomenon in the biological literature. This effect describes as a positive relation between population density and the per capita growth rate. Allee function has the following property [21].

1. $f^{\prime}(\mathrm{y})=\frac{y}{(\mathrm{~m}+\mathrm{y})^{2}}>0$ for all $y \in(0, \infty)$, it means that Allee effect decreases as density increases.

$2 . \lim _{y \rightarrow \infty} f(\mathrm{y})=1$, that is, the Allee effect vanishes at high densities.

Many researchers have studied dynamical behavior of the predator-prey system with Allee effect [17-20].

The outline of this paper is as follows. In section 2, the stability conditions of the coexistence fixed points are discussed. In section 3, Flip bifurcation analysis is investigated by using bifurcation theory. $\delta$ parameter is selected as a bifurcation parameter. Furthermore, direction of Flip bifurcation is obtained by using normal form theory [22-24]. Moreover, some numerical simulations are presented to illustrate the analytic finding.

\section{LOCAL STABILITY ANALYSIS}

In this section, we discuss stability conditions of the coexistence fixed point of model (2).

Lemma 1 Assume $F(\lambda)=\lambda^{2}+p_{1} \lambda+p_{0}$, where $p_{1}$ and $p_{0}$ are two real constants and let $F(1)>0$. Suppose that $\lambda_{1}$ and $\lambda_{2}$ are two roots of $F(\lambda)=0$. Then $\left|\lambda_{1}\right|<1$ and $\left|\lambda_{2}\right|<1$ if and only if $F(-1)>0$ and $p_{0}<1$.

Definition 1. A fixed point $\left(\mathrm{x}^{*}, \mathrm{y}^{*}\right)$ is called sink if $\left|\lambda_{1}\right|<1$ and $\left|\lambda_{2}\right|<1$, and it is locally asymptotically stable. 
Theorem 1. If $\mathrm{b}_{2}>a_{22} \mathrm{~m}$, the system (2) has an only positive coexistence point $\mathrm{E}\left(\mathrm{x}^{*}, \mathrm{y}^{*}\right)=\left(\frac{b_{1} a_{22}+a_{12}\left(\mathrm{~b}_{2}-a_{22} \mathrm{~m}\right)}{a_{11} a_{22}}, \frac{\mathrm{b}_{2}-a_{22} \mathrm{~m}}{a_{22}}\right)$ and $\mathrm{E}\left(\mathrm{x}^{*}, \mathrm{y}^{*}\right)$ coexistence fixed point is local asymptotically stable if $0<\delta<\min \left\{\delta_{1}, \delta_{2}\right\}$ where $\delta_{1}=\frac{2 b_{2}}{\left(\mathrm{~b}_{2}-\mathrm{ma}_{22}\right)^{2}+b_{2}^{2}}$ and $\delta_{2}=-\frac{2 a_{22}}{\mathrm{~b}_{1} a_{22}+a_{12}\left(\mathrm{~b}_{2}-\mathrm{ma}_{22}\right)}$.

Proof: The fixed point of the system (2) satisfy the following equations

$$
\begin{aligned}
& x^{*}=x^{*}+\delta\left(x^{*}\left(\mathrm{~b}_{1}-a_{11} x^{*}\right)+a_{12} x^{*} y^{*}\right) \\
& y^{*}=y^{*}+\delta\left(y^{*} \mathrm{~b}_{2} \frac{y^{*}}{m+y^{*}}-a_{22} y^{*}\right)
\end{aligned}
$$

It is clear that $\mathrm{E}\left(\mathrm{x}^{*}, \mathrm{y}^{*}\right)=\left(\frac{b_{1} a_{22}+a_{2}\left(\mathrm{~b}_{2}-a_{22} \mathrm{~m}\right)}{a_{11} a_{22}}, \frac{\mathrm{b}_{2}-a_{22} \mathrm{~m}}{a_{22}}\right)$ is coexistence positive fixed point of the system (2) if $b_{2}>a_{22} m$. The Jacobian matrix of the model (2) at $\mathrm{E}\left(\mathrm{x}^{*}, \mathrm{y}^{*}\right)$ coexistence fixed point is following form:

$$
J(\mathrm{E})=\left[\begin{array}{cr}
1-\frac{2 \delta}{\delta_{2}} & -\frac{2 a_{12} \delta}{a_{11} \delta_{1}} \\
0 & 1-\frac{2 \delta}{\delta_{1}}
\end{array}\right]
$$

where $\delta_{1}=\frac{2 b_{2}}{\left(\mathrm{~b}_{2}-\mathrm{ma}_{22}\right)^{2}+b_{2}^{2}}$ and $\delta_{2}=-\frac{2 a_{22}}{\mathrm{~b}_{1} a_{22}+a_{12}\left(\mathrm{~b}_{2}-\mathrm{ma}_{22}\right)}$.

The characteristic equation of the matrix $J(\mathrm{E})$ is

$$
\lambda^{2}+\left(-2+\frac{2 \delta}{\delta_{1}}+\frac{2 \delta}{\delta_{2}}\right) \lambda+\left(1-\frac{2 \delta}{\delta_{1}}\right)\left(1-\frac{2 \delta}{\delta_{2}}\right)=0
$$

The two eigenvalues of $J(\mathrm{E})$ are $\lambda_{1}=1-\frac{2 \delta}{\delta_{1}}$ and $\lambda_{2}=1-\frac{2 \delta}{\delta_{2}}$. From definition 1 , we get $\delta<\delta_{1}$ and $\delta<\delta_{2}$. This completes the proof.

Example 1. For the parameter values $a_{11}=1, a_{12}=1, a_{22}=1, b_{1}=1, b_{2}=2, m=1.2, \delta=0.5$ and initial condition $\left(\mathrm{x}_{0}, \mathrm{y}_{0}\right)=(1.5,1.6)$, the positive coexistence fixed point of the model (2) is obtained as $\mathrm{E}$ $\left(\mathrm{x}^{*}, \mathrm{y}^{*}\right)=(1.8,0.8)$. From Figure 1, the fixed point $\mathrm{E}\left(\mathrm{x}^{*}, \mathrm{y}^{*}\right)=(1.8,0.8)$ of the system (2) is local asymptotically stable for $\delta<\delta_{2}=1.11111111111$ which shows the correctness of the Theorem 1 . 

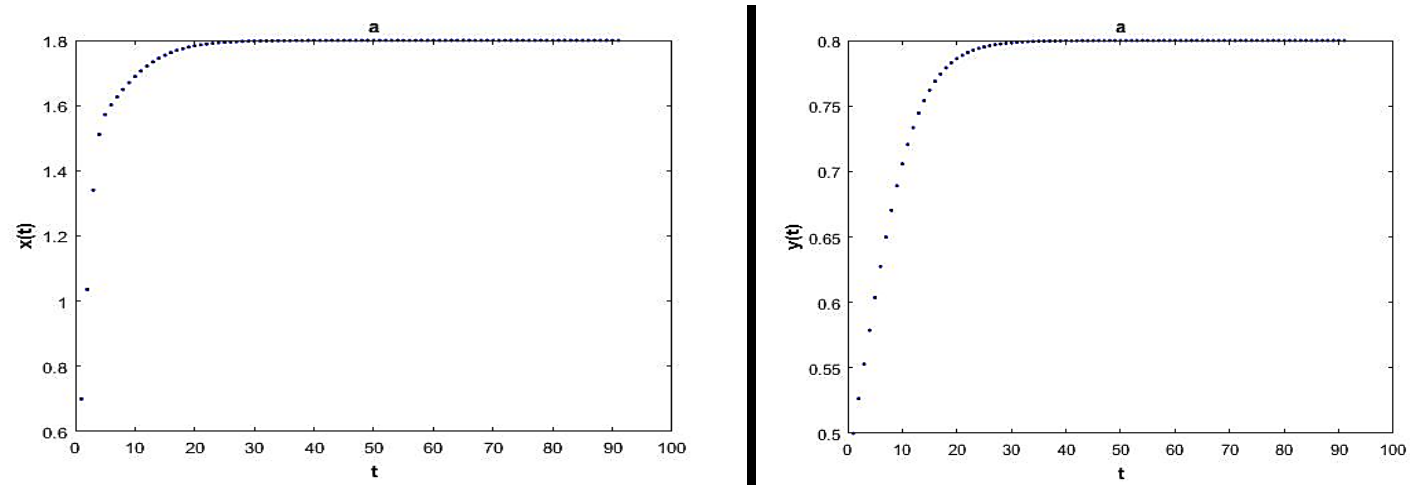

Figure1. A stable coexistence fixed point for the system (2).

\section{FLIP BIFURCATION ANALYSIS}

Theorem 2. [6,24] For the system (2), one of the eigenvalues is -1 and the other eigenvalues lie inside the unit circle if and only if

a) $F(1)=1+\mathrm{p}_{1}+p_{0}>0$

b) $F(-1)=1-p_{1}+p_{0}=0$

c) $D_{1}^{+}=1+p_{0}>0$

d) $D_{1}^{-}=1-p_{0}>0$.

Lemma 2. (Eigenvalue Assignment). Let $a_{12}>m a_{22}$ and $0<\delta<2 \delta_{1}$. If $\delta_{F}=\delta_{2}$ then the eigenvalue assignment condition of Flip Bifurcation in Theorem 2.

Proof. From characteristic equation (5), we can write

$$
\begin{aligned}
& p_{1}=-2+\frac{2 \delta}{\delta_{2}}+\frac{2 \delta}{\delta_{1}} \\
& p_{0}=\left(1-\frac{2 \delta}{\delta_{2}}\right)\left(1-\frac{2 \delta}{\delta_{1}}\right)
\end{aligned}
$$

Condition (a) of theorem 2 gives the inequality

$$
F(1)=\frac{4 \delta^{2}}{\delta_{1} \delta_{2}}>0
$$

which always satisfied since $\delta_{1}>0, \delta_{2}>0$ and $\delta>0$. 


$$
F(-1)=4-\frac{4 \delta}{\delta_{2}}-\frac{4 \delta}{\delta_{1}}+\frac{4 \delta^{2}}{\delta_{1} \delta_{2}}=0
$$

which gives $\delta_{1}^{*}=\delta_{1}$ and $\delta_{1}^{*}=\delta_{2}$.

From condition (c) of theorem 1, we get the inequality

$$
D_{1}^{+}=\frac{2\left(\delta_{1} \delta_{2}-\delta \delta_{2}-\delta \delta_{1}+2 \delta^{2}\right)}{\delta_{1} \delta_{2}}>0 .
$$

Eq.(10) leads to $\delta_{1} \delta_{2}+2 \delta^{2}>\delta\left(\delta_{1}+\delta_{2}\right)$ which is always satisfied.

$$
D_{1}^{-}=\frac{2 \delta\left(\delta_{1}+\delta_{2}-2 \delta\right)}{\delta_{1} \delta_{2}}>0
$$

which leads to $0<\delta<\frac{\delta_{1}+\delta_{2}}{2}$.

Now, it is easy to see that the Jacobian matrix $J$ have the eigenvalues $\lambda_{1}=-1$ and $\lambda_{2}\left(\delta^{*}\right)=1-\frac{2 \delta_{2}}{\delta_{1}}$ which show the correctness Lemma 2.

To compute the coefficients of the normal form, we convert the origin of the coordinates to coexistence fixed point $\mathrm{E}\left(\mathrm{x}^{*}, \mathrm{y}^{*}\right)=\left(\frac{b_{1} a_{22}+a_{12}\left(\mathrm{~b}_{2}-a_{22} \mathrm{~m}\right)}{a_{11} a_{22}}, \frac{\mathrm{b}_{2}-a_{22} \mathrm{~m}}{a_{22}}\right)$ by the change of variables

$$
\begin{aligned}
& x=x^{*}-X \\
& y=y^{*}-Y
\end{aligned}
$$

Then, this system can be rewritten in the form

$$
X_{t+1}=\mathrm{JX}_{t}+\frac{1}{2} B\left(\mathrm{X}_{t}, \mathrm{X}_{t}\right)+\frac{1}{2} \mathrm{C}\left(\mathrm{X}_{t}, \mathrm{X}_{t}, \mathrm{X}_{t}\right)+\mathrm{O}\left(\mathrm{X}_{t}^{4}\right)
$$

where

$$
J=J\left(\delta^{*}\right)
$$

And the multilinear functions $\mathrm{B}$ and $\mathrm{C}$ are defined by

$$
B_{i}(\mathrm{x}, \mathrm{y})=\left.\sum_{j, k=1}^{2} \frac{\partial^{2} F_{i}(\varepsilon, 0)}{\partial \varepsilon_{j} \partial \varepsilon_{k}}\right|_{\varepsilon=0} x_{j} y_{k}, i=1,2
$$

and 


$$
C_{i}(\mathrm{x}, \mathrm{y}, \mathrm{z})=\left.\sum_{j, k, l=1}^{2} \frac{\partial^{3} F_{i}(\varepsilon, 0)}{\partial \varepsilon_{j} \partial \varepsilon_{k} \partial \varepsilon_{l}}\right|_{\varepsilon=0} x_{j} y_{k} \mathrm{z}_{l}, i=1,2
$$

The values of $B$ and $C$ of the system can be obtained as

$$
\begin{gathered}
B_{1}(\mathrm{x}, \mathrm{y})=\frac{2 \delta\left(-\mathrm{b}_{2}^{6}+\mathrm{b}_{2}^{4} \mathrm{a}_{22}^{2} \mathrm{~m}^{2}\right)}{\mathrm{b}_{2}^{6}} x_{2} y_{2}, \\
B_{2}(\mathrm{x}, \mathrm{y})=0 \\
C_{1}(\mathrm{x}, \mathrm{y}, \mathrm{z})=\left(-\frac{6 \delta a_{22}^{4} m^{2}}{b_{2}^{3}}\right) x_{2} y_{2} z_{2} \\
C_{2}(\mathrm{x}, \mathrm{y}, \mathrm{z})=0
\end{gathered}
$$

and $\delta=\delta_{2}$.

We know that $\mathrm{J}\left(\delta_{2}\right)$ has eigenvalue $\lambda_{1}\left(\delta_{2}\right)=-1$, and the corresponding eigenspace $E^{c}$ is onedimensional and spanned by an eigenvector $q \in R^{2}$ such that $\mathrm{J}\left(\delta_{2}\right) \mathrm{q}=-\mathrm{q}$. Let $p \in R^{2}$ be the adjoint eigenvector, that is, $\mathbf{J}^{t}\left(\delta_{2}\right) \mathrm{p}=-p$. By calculation we obtain

$$
\begin{gathered}
q \sim(1,0)^{T}, \\
p \sim\left(\frac{\left(\delta_{2}-\delta_{1}\right) \mathrm{a}_{11}}{\mathrm{a}_{12} \delta_{1}}, 1\right)^{T} .
\end{gathered}
$$

In order to normalize $p$ with respect to $q$, we denote

$$
p=\left(1, \frac{\delta_{1} a_{2}}{\left(\delta_{2}-\delta_{1}\right) \mathrm{a}_{11}}\right)^{T}
$$

To determine the direction of the flip bifurcation, the sign of the critical normal form coefficient $c(0)$ is computed by the below formula:

$$
c(0)=\frac{1}{6}\langle p, C(\mathrm{q}, \mathrm{q}, \mathrm{q})\rangle-\frac{1}{2}\left\langle p, \mathrm{~B}\left(\mathrm{q},(\mathrm{J}-\mathrm{I})^{-1} \mathrm{~B}(\mathrm{q}, \mathrm{q})\right)\right\rangle .
$$

From the above analysis, we give below theorem.

Theorem 3. Suppose that $\mathrm{E}\left(\mathrm{x}^{*}, \mathrm{y}^{*}\right)$ is a positive coexistence fixed point of the system (2). Lemma 2 holds and $\mathrm{c}(0) \neq 0$, then system (2) undergoes a flip bifurcation at the fixed point $\mathrm{E}\left(\mathrm{x}^{*}, \mathrm{y}^{*}\right)$ when the parameter $\delta$ varies in a small neighborhood of $\delta_{2}$. Moreover, if $\mathrm{c}(0)>0$ (respectively, $\left.\mathrm{c}(0)<0\right)$, then the period-2 orbits that bifurcate from $\mathrm{E}\left(\mathrm{x}^{*}, \mathrm{y}^{*}\right)$ are stable (respectively, unstable). 
Example 2. Taking parameters $a_{11}=1, a_{12}=1, a_{22}=1, b_{1}=1, b_{2}=2, m=1.2$, the coexistence fixed point of the system (2) is obtained as $\left(\mathrm{x}^{*}, \mathrm{y}^{*}\right)=(1.8,0.8)$. The critical value of Flip bifurcation point is obtained as $\delta_{F}=\delta_{2}=1.11111111111$. The Jacobian matrix $J\left(\delta_{2}\right)$ of the system (2) is given;

$$
J\left(\delta_{2}\right)=\left[\begin{array}{cc}
-1 & 2 \\
0 & 0.6444444444
\end{array}\right]
$$

The characteristic polynomial of the system (2) at the coexistence fixed point $\left(\mathrm{x}^{*}, \mathrm{y}^{*}\right)=(1.8,0.8)$ is written by

$$
F(\lambda)=\lambda^{2}+0.3555555556 \lambda-0.6444444444
$$

The eigenvalues of the system (2) are $\lambda_{1}=-1$ and $\lambda_{2}=0.6444444444<1$. Moreover, $F(1)=0.7111111116>0, \quad F(-1)=0, \quad D_{1}^{+}=0.3555555556>0, D_{1}^{-}=1.6444444444>0 . \quad$ This verifies Theorem 2. Also, the eigenvectors $q, \mathrm{p} \in \mathrm{R}^{2}$ corresponding to $\lambda_{1}\left(\delta_{2}\right)=-1$ are

$$
q \sim(1,0)^{T}
$$

and

$$
p \sim(-0.8222222222,1)^{T} .
$$

To achieve the necessary normalization $\langle p, q\rangle=1$, we get

$$
q=(1,0)^{T}
$$

$$
p=(0.9999999998,-1.216216216)^{T} \text {. }
$$

By using the formula (12), the critical norm form coefficient $c(0)=0.36452221>0$. Therefore, a unique and stable period-two cycle bifurcation from $\left(\mathrm{x}^{*}, \mathrm{y}^{*}\right)=(1.8,0.8)$ for $\delta>\delta_{2}=1.111111111$. In Figure 2 , the phase portraits of the system (2) for different values of the $\delta$ are given. It is clear that system (2) undergoes Flip bifurcation in critical value of $\delta_{F}=1.11111111$ parameter. 

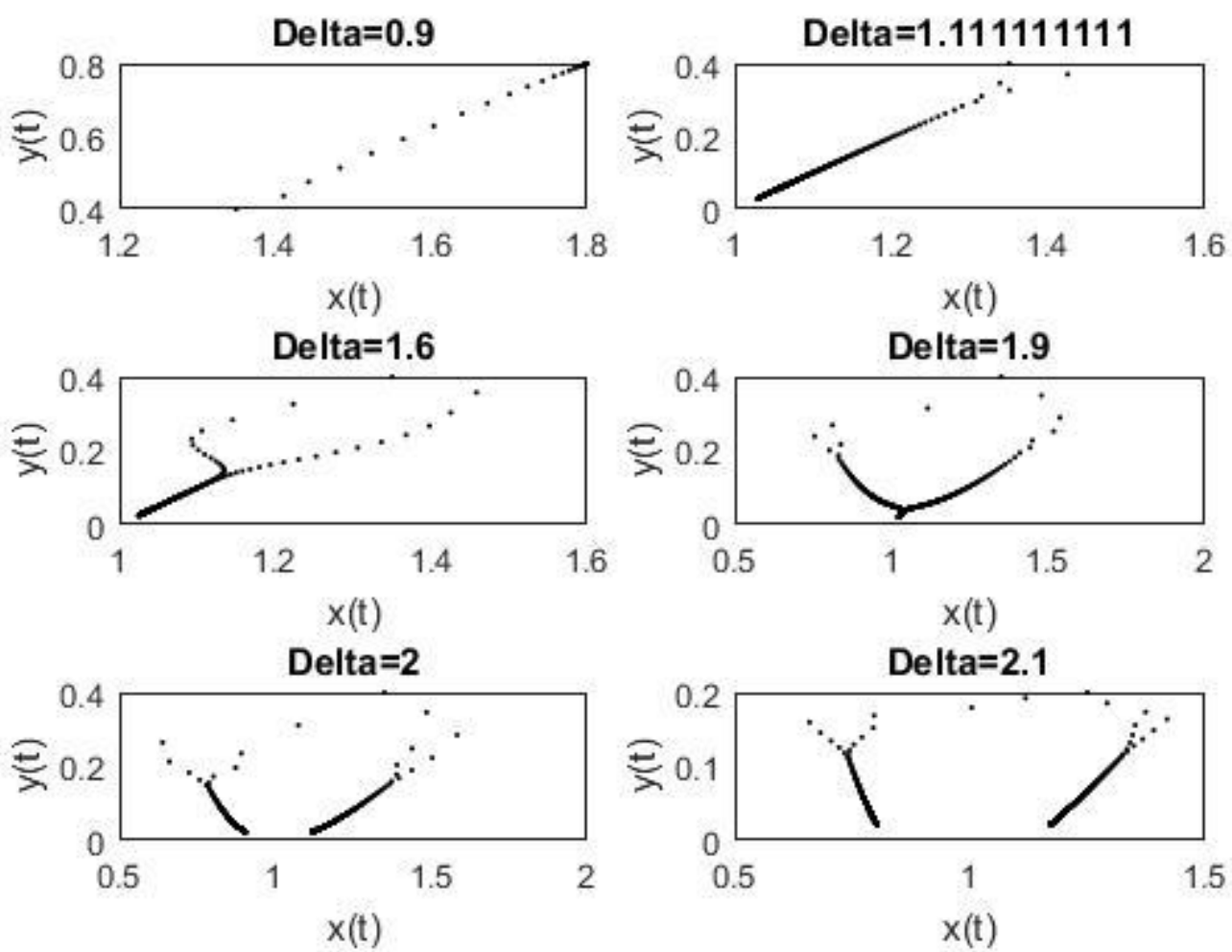

Figure 2. Phase portrait for different values of $\delta$ parameter.

\section{CONCLUSION}

In this study, the dynamics of a discrete-time prey-predator model with Allee effect has been investigated. Local stability conditions of the coexistence fixed point of the model are analyzed. It is shown that Flip bifurcation has been observed in the presented model. The parameter $\delta$ is selected as a bifurcation parameter. When $\delta$ reaches to $\delta_{F}=1,11111111111$, the system (2) goes a flip bifurcation (see Figure 2). So, we can say that $\delta$ parameter has a strong effect on the system.

\section{REFERENCES}

[1]. He Z. and Lai X., Bifurcation and Chaotic Behavior of a Discrete-Time Predator-Prey System , Nonlinear Analysis:Real World Applications., 12 (2011) 403-417.

[2]. Salman S. M., Yousef A. M. and Elsadany A. A., Stability, Bifurcation Analysis and Chaos Control of a Discrete Predator-Prey System with Square Root Functional Response, Chaos Solitons \& Fractals., 93 (2016) 20-31.

[3]. Khan A.Q., Neimark-Sacker Bifurcation of a Two-Dimensional Discrete-Time Predator-Prey Model, Springer Plus., 5 (2016) 126.

[4]. Kartal Ş., Mathematical Modeling and Analysis of Tumor-Immune System Interastion by Using Lotka-Volterra Predator-Prey Like Model with Piecewise Constant Arguments., Periodicals of Engineering and Natural Science.s, 2-1 (2014).

[5]. Kartal Ş., Dynamics of A Plant-Herbivore Model with Differential-Difference Equations, Cogents Mathematics., 3: 1136198 (2016).

[6]. Kartal Ş., Flip and Neimark-Sacker Bifurcation in a Differential Equation with Piecewise Constant Arguments Model, Journal of Difference Equations and Applications., 23-4 (2017) 763-778. 
[7]. Kartal Ş. and Gurcan F., Global Behaviour of a Predator-Prey Like Model with Piecewise Constant Arguments, Journal of Biological Dynamics., 9-1 (2015) 159-171.

[8]. Elabbasy E. M., Elsadany A. A. and Zhang Y., Bifurcation Analysis and Chaos in a Discrete Reduced Lorenz System, Applied Mathematics and Computation., 228 (2014) 184-194.

[9]. Din Q., Complexity and Choas Control in a Discrete-Time Prey-Predator Model, Commun Nonlinear Sci. Numer. Simulat., 49 (2017) 113-134.

[10]. Din Q., Stability, Bifurcation Analysis and Chaos Control for a Predator-Prey System, Journal of Vibration and Control., https://doi.org/10.1177/1077546318790871 (2018).

[11]. Zhang J., Deng T., Chu Y., Qin S., Du W. and Luo H., Stability and Bifurcation Analysis of a Discrete Predator-Prey Model with Holling type III Functional Response, Journal of Nonlinear Science and Applications., 9 (2016) 6228-6243.

[12]. Liu X. and Xiao D., Complex Dynamics Behaviors of a Discrete-Time Predator-Prey System, Chaos Solitons \&Fractals., 32 (2007) 80-94.

[13]. Rana S. M.,Bifurcation and Complex Dynamics of a Discrete-Time Predator-Prey System, Computational Ecology and Software., 5-2 (2015) 187-200.

[14]. Rana S. M. and Kulsum U., Bifurcation Analysis and Chaos Control in a Discrete-Time PredatorPrey System of Leslie Type with Simplified Holling Type IV Functional Response, Hindawi., Article ID 9705985 (2017).

[15]. Rana S. M., Bifurcation and Complex Dynamics of a Discrete-Time Predator-Prey System Involving Group Defense, Computational Ecology and Software., 5 -3 (2015) 222-238.

[16]. Hu Z., Teng Z. and Zhang L., Stability and Bifurcation Analysis of a Discrete Predator-Prey Model with Nonmonotonic Functional Response, Nonlinear Analysis: Real World Applications., 12 (2011) 2356-2377.

[17]. Zhou S., Liu Y. and Wang G., The Stability of Predator-Prey Systems Subject to the Allee Effects, Theoretical Population Biology., 67 (2005) 23-31.

[18]. Sen M., Banarjee M. and Morozou A., Bifurcation Analysis of a Ratio-Dependent Prey-Predator Model with the Allee Effect, Ecological Complexity., 11 (2012) 12-27.

[19]. Cheng L. and Cao H., Bifurcation Analysis of a Discrete-Time Ratio-Dependent Prey-Predator Model with the Allee Effect, Communication Nonlinear Sci. Numer. Simulat., 38 (2016) 288-302.

[20]. Kangalgil F. and Ak Gumus Ö.,Allee Effect in a New Population Model And Stability Analysis, Gen. Math. Notes., 35-1 (2016) 54-64.

[21]. Lin Q., Allee Effect Increasing the Final Density of the Species Subject to Allee Effect in a LotkaVolterra Commensal Symbiosis Model, Advance in Difference Equations., 2018-196 2018.

[22]. Kuznetsov Y. A., Elements of Applied Bifurcation Theory, Springer-Verlag, New York, NY, USA, 2nd edition, 1998.

[23]. Wiggins S., Introduction to Applied Nonlinear Dynamical System and Chaos, vol. 2, SpringerVerlag, New York, NY, USA, 2003.

[24]. Elaydi S. N., An Introduction to Difference Equations, Springer-Verlag, New York, NY, USA, 2005.

[25]. Kartal Ş., Multiple Bifurcations in an Early Brain Tumor Model with Piecewise Constant Arguments , International Journal of Biomathematics., 1-4 (2018) 1850055. 